\title{
How to survive earthquakes: the example of Norcia
}

\author{
Lopes, M., Sá, F.M., Ferreira, M., C. and Oliveira, C.S.
}

Instituto Superior Técnico, Lisboa, Dept of Civil Engineering

Oliveira, C.F.

Escola Superior de Tecnologia do Barreiro, Instituto Politécnico de Setúbal

\begin{abstract}
:
In this paper lessons are extracted from the comparison between the very different consequences that similar earthquakes had on the neighbouring tows of Norcia and Amatrice during the 2016 seismic crisis of central Italy. It was found that the differences in damage were essentially due to the previous strengthening of most houses in Norcia during the previous decades. This is also likely to lead to a much faster recover of the economy and livelihood in Norcia, as Amatrice needs to be completely rebuilt.
\end{abstract}

Keywords: earthquake, damage, strengthening

\section{INTRODUCTION}

On the 30st October 2016 an earthquake of magnitude 6.5 hit the town of Norcia, in central Italy. Due to the reduced epicentral distance the accelerations in Norcia were extremely high, with a value of the horizontal PGA=0,48g registered at the nearest seismic station (Luzi,2016). This is a very high value. Two months before, on 24th August, the neighboring village of Amatrice had been shaken by an earthquake slightly stronger. In this earthquake most of the constructions of Amatrice collapsed, the ones that did not collapse were so damaged that were useless, and hundreds of people died. Today it is a dead village, where nobody is allowed to enter freely. How is it possible to explain the differences between Norcia and Amatrice, how is it possible nobody died in Norcia? In order to find and document answers to these questions a KnowRISK team, with members of IST and INGV visited the affected zones during the last week of October 2016, during which several earthquakes hited Norcia and Amatrice. In fact the motivation for this field trip arised from the fact that during August earthquakes Norcia had already been strongly hit but not so strongly as would be later in October.

\section{CHARACTERISTICS OF THE SEISMIC ACTIONS}

Figure 1 shows the spectra for horizontal accelerations registered in stations located in Amatrice and Norcia. The Amatrice spectra refer to the earthquakes of $24^{\text {th }}$ August and the spectra for Norcia refer to the 30st October, as these were the strongest ones in each town and the ones that caused more damaged in each. 